\title{
Em busca de movimentos ausentes para motricidades emergentes: a relação entre Epistemologias do Sul e Motricidade Humana
}

\author{
In search of absent movements for emerging motricities: the relationship between Epistemologies of the \\ South and Human Motricity
}

En busca de movimientos ausentes de motricidades emergentes: la relación entre las epistemologías del sur y la motricidad humana

\author{
CARlos Nolasco 1 \\ Universidade de Coimbra, UC, Coimbra, Portugal
}

\begin{abstract}
RESUMO
Este ensaio tem como ponto de partida o reconhecimento de que o mundo contemporâneo se encontra numa situação de ambivalência, entre perigos e possibilidades, que não só desafiam o presente como equacionam o futuro. O desporto e o gesto desportivo, como fenômenos que resultam dos contextos em que são produzidos, encontram-se necessariamente nessa ambiguidade. Partindo das Epistemologias do Sul, enquanto proposta de resgate de dimensões epistêmicas e humanas ausentes do espaço hegemônico, e apresentadas como alternativas ao esgotamento da modernidade, propõe-se uma análise crítica das dinâmicas sociais do desporto, através da operacionalização dos conceitos de sociologia das ausências e de sociologia das emergências, sugerindo a emergência de outro desporto que vá ao encontro da perspectiva da motricidade humana na assunção da complexidade e da transcendência do gesto desportivo.
\end{abstract}

Palavras-chave: Epistemologias do Sul. Motricidade Humana. Interculturalidade. Desporto. Corpo.

\begin{abstract}
This essay has as its starting point the recognition that the contemporary world is in a situation of ambivalence, between dangers and possibilities, which not only challenge the present but also equate the future. Sport and sporting gesture, as phenomena that result from the contexts in which they are produced, are necessarily in this ambiguity. Starting from the Epistemologies of the South, as a proposal to rescue epistemic and human dimensions absent from the hegemonic space, and presented as alternatives to the exhaustion of modernity, a critical analysis of the social dynamics of sport is proposed through the operationalization of the concepts of sociology of absences and sociology of emergencies, suggesting the emergence of another sport that meets the perspective of human motricity, assuming the complexity and transcendence of the sporting gesture.
\end{abstract}

Keywords: Epistemologies of the South. Human Motricity. Interculturality. Sport. Body.

\section{RESUMEN}

Este ensayo tiene como punto de partida el reconocimiento de que el mundo contemporáneo se encuentra en una situación de ambivalencia, entre peligros y posibilidades, que no solo desafían el presente sino que también equiparan el futuro. El deporte y el gesto deportivo, como fenómenos que resultan de los contextos en los que se producen, se encuentran necesariamente en esta ambigüedad. Partiendo de las Epistemologías del Sur, como una propuesta para rescatar las dimensiones epistémicas y humanas ausentes del espacio hegemónico, y presentadas como alternativas al agotamiento de la modernidad, proponemos un análisis crítico de las dinámicas sociales del deporte, a través de la operacionalización de los conceptos de sociología de las ausencias y de sociología de las emergencias, sugiriendo la emergencia de otro deporte que cumpla con la perspectiva de la motricidad humana en el supuesto de la complejidad y trascendencia del gesto deportivo.

Palabras clave: Epistemologías del Sur. Motricidad humana. Interculturalidad Deporte. Cuerpo.

\footnotetext{
${ }^{1}$ Investigador do Centro de Estudos Sociais da UC. E-mail: cmsnolasco@gmail.com
} 


\section{INTRODUÇÃO}

Em dezembro de 2016, o Secretário-Geral das Nações Unidas eleito, António Guterres, no discurso de tomada de posse realçou a ambivalência da contemporaneidade. Um mundo de contradições e tensões ocultas, de imprevisibilidade, instabilidade e impunidade, de conflitos complexos e inter-relacionados, de guerras e terrorismo, de violação do Direito e de Direitos, de migrações e refugiados, das megatendências de mudanças climáticas, do crescimento demográfico, da insegurança alimentar, ao mesmo tempo em que é um mundo de progressos extraordinários e surpreendentes a nível tecnológico e científico, onde se verificam melhorias dos indicadores sociais básicos e diminuição da pobreza absoluta ${ }^{2}$. Os diagnósticos revelam a ambiguidade na persistência de velhos perigos, agora ampliados e intensificados pelas evoluções tecnológicas, mas também um admirável mundo novo de possibilidades proporcionado pela evolução do conhecimento, que poderá converter-se igualmente em perigos, consoante a utilização que se faça dessas possibilidades.

Num mundo assim caraterizado, as inquietações suscitam perguntas pertinentes a exigir respostas vigorosas. Como refere Boaventura de Sousa Santos, "[...] vivemos um tempo de perguntas fortes e respostas fracas" (2008, p. 13), em que as perguntas são feitas não apenas às opções de vida individual e coletiva, bem como ao horizonte de possibilidades de escolha, sendo as respostas fracas porque são dadas sem colocar em causa o status quo do paradigma dominante, recriando soluções já anteriormente apresentadas. Estas respostas, que antes satisfizeram a perplexidade da modernidade, em tempo de transição paradigmática revelam-se insuficientes e desajustadas. São respostas fracas, dadas por entidades do Norte Global ${ }^{3}$, que se impõem como absolutas, traduzidas em conhecimento, política e economia hegemônicas, satisfazendo essencialmente o auditório dessa parte. O Sul Global sente essas respostas como imposições, violências e exclusões, reduzindo ou suprimindo totalmente as possibilidades de uma vida digna e decente. Assim, a imagem de um mundo uniforme e homogêneo, propalada pela concepção de globalização (GIDDENS, 1992), revela-se incongruente. A realidade acontece de forma heterógena, com as dimensões econômicas, sociais, políticas, culturais, religiosas e jurídicas a entrelaçarem-se das mais diversas formas, dissipando a percepção do mundo como um todo. Os sucessivos relatórios produzidos sobre o estado do mundo mostram como a riqueza, o desenvolvimento e a miséria se distribuem de forma diferenciada pela humanidade, beneficiando sistematicamente o norte em detrimento do sul ${ }^{4}$. No mundo caraterizado pelo Secretário-Geral da ONU as possibilidades de futuro parecem diluírem-se num pessimismo conformado (SANTOS; ARAÚJO; BAUMGARTEN, 2016) sobre as

\footnotetext{
${ }^{2}$ Discurso do Secretário-Geral das Nações Unidas, proferido em 12 de Dezembro de 2016, dia em que tomou posse. Disponível em: <https://www.un.org/sg/es/content/sg/speeches/2016-12-12/secretarygeneral-designate-ant\%C3\%B3nio-guterres-oath-office-speech>. Acesso em: 2 jul. 2019.

${ }^{3}$ Considerando que serão recorrentes, neste texto, as referências ao Norte Global e Sul Global, importa explicitar os sentidos que lhe são inerentes. São referências antagônicas de duas metáforas espaciais que correspondem de forma ampla à divisão do mundo. Esta concepção do Norte e Sul globais sobrepõe-se em parte ao norte e sul geográficos, cabendo ao Sul o conjunto dos países e regiões do mundo que foram submetidas ao colonialismo europeu, e que com exceção da Austrália e Nova Zelândia, não atingiram níveis de desenvolvimento semelhantes ao Sul global, ou seja à Europa e América do Norte. A sobreposição não é total porque no norte geográfico há grupos sociais que foram sujeitos à dominação capitalista e colonial, bem como no sul geográficos há elites que beneficiaram dos privilégios dessa mesma dominação (SANTOS; MENESES, 2009). Nesta dicotomia o Sul comporta o sentido de uma metáfora do sofrimento humano injusto provocado pelo capitalismo, pelo colonialismo e pelo patriarcado. 4 A este propósito veja-se o mais recente relatório das Nações Unidas sobre a pobreza no mundo (UNITED NATIONS, 2019).
} 
possibilidades de futuro, pelo que é urgente a apresentação de alternativas paradigmáticas que respondam de forma consistente às questões que lhe são colocadas.

Num momento de questionamento crítico, em que se colocam perguntas fortes ao modelo político e econômico dominante e ao paradigma epistemológico hegemônico, o desporto e o gesto desportivo enquanto produto e expressão desse contexto, não pode deixar de ser questionado. Tal como a modernidade, também o desporto deixou por cumprir muitas das promessas que se havia proposto realizar. $\mathrm{O}$ desporto, e em particular o desporto de alta competição, em vez de se constituir como uma das reservas morais da sociedade, como elemento de bem-estar e fator de emancipação, metamorfoseou-se com a política, adulterou-se com a economia e frustrou-se com a violência, o racismo, a discriminação e a hiper-robotização dos atletas. Levanta-se então a questão sobre o que o desporto poderia ser, mas não é? Poderá o desporto ser expressão de emancipação social de culturas e povos? Poderá contribuir para uma ética diferente? Poderá contribuir para a harmonia social? Para a paz política? Para o fim da relação desequilibrada entre os povos? Permite o desporto outra gramática da dignidade humana? Poderá o gesto desportivo ser uma forma de emancipação? Outro desporto é possível?

As respostas não são simples. Quem faz a apologia encantatória do desporto ensaiará de forma acrítica respostas positivas sobre os seus méritos, no entanto a realidade mostra o enviesamento das mesmas.

A proposta deste texto é ensaiar uma análise do desporto à luz das Epistemologias do Sul, tendo em consideração dois conceitos fundamentais: a sociologia das ausências e a sociologia das emergências. A partir da percepção do corpo desportivo e das dinâmicas contemporâneas do desporto enquanto fenômeno social, assume-se um olhar crítico da realidade no resgate de ausências que permitam a emergência de outro desporto, e que vão ao encontro da Ciência da Motricidade Humana, tal como foi proposta por Manuel Sérgio, enquanto assunção da complexidade e transcendência do gesto desportivo (SÉRGIO, 1994).

Este texto está estruturado em três partes: na primeira, a partir de um fato ocorrido em 1904, parte-se em busca de outros corpos que estiveram ausentes do panorama desportivo, e que, no entanto são detentores de uma motricidade própria e emergente; na segunda parte, analisa-se a forma como as Epistemologias do Sul dão uma resposta forte às questões colocadas nos tempos que correm, procurando ter como entidade em discussão o fenômeno desportivo; na terceira e última parte, ensaiar-se-á uma relação de complementaridade entre Epistemologias do Sul e Motricidade Humana, na busca de motricidades emergentes.

\section{OS CORPOS DESPORTIVOS DOS DIAS ANTROPOLÓGICOS}

Conta-nos a História que em 1904, em St. Louis, no estado do Missouri, Estados Unidos, realizou-se a terceira edição dos Jogos Olímpicos da Era Moderna. Jogos que seriam marcados, entre outros fatos, pelos Dias Antropológicos ${ }^{5}$. Inicialmente as Olimpíadas estiveram agendadas para Chicago, contudo, por decisão do Presidente americano Theodore Roosevelt, e contra a vontade de Pierre de Coubertin, Presidente do Comitê Olímpico Internacional, o evento realizar-se-ia em St. Louis, inserido na Louisiana Purchase Exhibition, uma pretensa exposição universal que celebrava o centenário da compra do território da Louisiana pelos Estados Unidos à França. Porque

\footnotetext{
${ }^{5}$ Para uma leitura ampla dos Dias Antropológicos consultar Brownell (2008) e Molinari (2018).
} 
se considerou ocupar todo o período da exposição com provas desportivas, o comitê organizador reservou dois dias, dentro da programação dos Jogos Olímpicos, para um evento que ficou conhecido como Dias Antropológicos. Simplesmente, consistia em reunir todos os indivíduos etnicamente exóticos presentes na Exposição, enquanto nativos representantes de lugares distantes e estranhos, colocando-os a disputar provas olímpicas num dia, e no seguinte, a mostrarem as suas habilidades nativas. Assim, convertidos em atletas olímpicos por um dia, foram reunidos indivíduos de várias etnias, inclusive nativos norte americanos. Como expectável, a sua participação nas diversas provas olímpicas, foi desastrosa, o que alimentou os comentários depreciativos sobre o desempenho desses atletas improvisados, ao mesmo tempo em que, por analogia, se valorizavam as proezas dos verdadeiros atletas olímpicos, quase todos de origem caucasiana. Para gozo geral, esses "atletas antropológicos" foram ainda, num segundo dia, chamados a participar em provas como a subida ao pau de sebo, trepar a árvores, ou fazerem tiro com arco e flecha. O único observador do Comitê Olímpico Internacional presente em St. Louis, o húngaro Ferenc Kemény, irritado, escreveria:

[...] não estive presente apenas num evento desportivo, mas numa feira onde houve desporto e artificio, e onde monstros foram exibidos para o escárnio geral. Estes homens, de todas as idades, das mais diferentes estaturas, de cores variadas, nunca ouviram antes falar de arremesso de peso, de corrida de obstáculos, de uma pista que exige do corredor conhecimento e preparação específica. A sua gesticulação provocava risos revoltantes (MALLON, 1994, p. 12).

Em reação, Pierre de Coubertin de forma premonitória escreveu que "[...] esta charada ultrajante certamente perderá o seu caráter apelativo quando homens negros, homens vermelhos e homens amarelos aprenderem a correr, pular e jogar, deixando os homens brancos para trás. Então haverá progresso" (EICHBERG, 2008, p. 347).

Os Dias Antropológicos aconteceram com base numa concepção de corpo e movimento, fundada na crença da inferioridade dos corpos racializados, e na superioridade dos corpos brancos, numa argumentação de discriminação essencial, muito comum na transição do século XIX para o século XX, e legalmente fundamentada pelo pensamento colonial da época (MENESES, 2010, p. 70). A inaptidão olímpica desses corpos negros, amarelos e vermelhos em 1904, justificava a sua exclusão da competição e simultaneamente a omnipresença dos atletas brancos ${ }^{6}$. Esses corpos estavam longe da concepção atlética, nem tão pouco tinham sido sujeitos a qualquer tipo de educação ideológica da prática desportiva moderna, em que o corpo como máquina é passível de aperfeiçoamento no sentido da sua máxima rentabilização motora, tendo como objetivo a concretização do lema Citius, Altius, Fortius. Para o ideário olímpico, todos os corpos sendo trabalhados por um moderno e racional programa de educação física, seriam passíveis desse aperfeiçoamento e desempenho.

Não se confunde aqui a bizarria desses dias antropológicos com os ideais olímpicos. Os Jogos Olímpicos são um tempo de exceção, colocando-se o desporto ao serviço do desenvolvimento harmonioso dos seres humanos, promovendo a fraternidade e amizade entre povos, favorecendo o estabelecimento de uma sociedade pacífica e

\footnotetext{
${ }^{6}$ Não deixa de ser irônico que os Jogos de St. Louis sejam aqueles onde pela primeira vez um atleta negro foi medalhado. O estadunidense George Poage ganhou duas medalhas de bronze em provas de atletismo. Disponível em: 〈https://www.olympic.org/george-poage>. Acesso em: 23 ago. 2019. Também resulta curioso que a África do Sul seja referida como o primeiro país africano a participar numas olimpíadas (LUCAS, 1905), sendo que os seus representantes não eram atletas, mas sim figurantes de um espetáculo em exibição na Feira Mundial, e que participaram na maratona com a designação étnica de zulus (VAN DER MERWE, 1999).
} 
comprometida com a dignidade humana ${ }^{7}$. O símbolo dessa união de povos é a bandeira olímpica, onde num fundo branco se entrelaçam cinco anéis de cor azul, amarela, negra, verde e vermelha, em representação de cada um dos continentes ${ }^{8}$. Contudo, em St. Louis, nesse ano de 1904, não foram apenas os indivíduos etnizados e racializados que foram depreciados, remetidos para a condição colonial de corpos sem valor. Nessas olimpíadas apenas participaram seis mulheres, sendo esses corpos femininos, constrangidos na sua expressão e desempenho por uma ancestralidade patriarcal, que as remetia para provas sem contato físico, sendo os seus gestos desportivos concebidos numa lógica essencialmente estética. Também estiveram ausentes os corpos profissionais, daqueles para quem a prática desportiva constitui uma forma de rendimento, interditados pelas entidades olímpicas com base numa concepção aristocrática de jogo e com o argumento de que a sua participação constituía uma adulteração da verdade desportiva. Os corpos com deficiência também estiveram ausentes, desde logo porque não se consideravam aptos para o desporto nem tão pouco havia modalidades adaptadas. Os corpos masculinos, predominantemente brancos, atléticos, e amadores, herdeiros dos heróis olímpicos da antiguidade e pretensos modelos da modernidade, constituíam os corpos hegemônicos da cultura olímpica.

Estava-se então no início do século XX, um tempo de otimismo. As sucessivas transformações sociais, políticas, urbanas, industriais, científicas e tecnológicas alimentavam a crença na inevitabilidade do progresso, e centravam a história na dinâmica dos grandes impérios. Um otimismo breve, desmoralizado pela era dos extremos que se seguiu (HOBSBAWM, 1994), e pela ameaça apocalíptica do nuclear. No devir histórico até à contemporaneidade, foram muitos os corpos interditados à prática desportiva. Por exemplo, em Moçambique, em 1931, afirmava-se ${ }^{9}$ que os "indígenas" apenas estavam aptos para atividades atléticas de natureza utilitária, como a caça ou a pesca, e que as suas manifestações lúdicas, cheias de elementos gímnicos, eram disso reflexo, pelo que se defendia que os desportos passíveis de serem acessíveis aos nativos eram a marcha, corrida, saltos, lutas, entre outros, sendo-lhes interditadas as atividades atléticas com a complexidade dos desportos praticados pelos europeus (DOMINGOS, 2006). No final dos anos 50, ainda em Moçambique, os futebolistas negros eram impedidos de integrar o plantel das equipes dos colonizadores, pelo que tinham que se organizar num campeonato alternativo, e é apenas com a percepção da mais-valia competitiva e financeira desses corpos negros, que os mesmos são cooptados pelas equipas de brancos, e posteriormente transferidos e apropriados pela metrópole ${ }^{10}$ (DOMINGOS, 2012).

Muitos foram os corpos nativos que progressivamente foram absorvidos pela metamorfose que converteu o desporto em fenômeno social identitário, em fato político, e essencialmente num interesse econômico/financeiro (BESNIER; BROWNELL, 2012). Contudo, há ainda muitos outros corpos questionados, encobertos, ausentes, como

\footnotetext{
${ }^{7}$ Estes princípios foram rescritos nas sucessivas edições da Carta Olímpica, como se pode verificar na $\begin{array}{lllll}\text { versão } & \text { de } & \text { 2019, } & \text { disponível } & \text { em }\end{array}$ https://stillmed.olympic.org/media/Document\%20Library/OlympicOrg/General/ES-OlympicCharter.pdf\#_ga=2.42212837.133595414.1569598653-1181992968.1569598653>, acesso em 15 de junho de 2019,

${ }^{8}$ O símbolo olímpico dos cinco anéis foi utilizado pela primeira vez em 1914, e utilizado como bandeira olímpica nos Jogos Olímpicos de 1920, em Antuérpia.

9 Os argumentos são apresentados por Ismael Mário Jorge, capitão do exército português em Moçambique, e que em 1931 apresentou um atito, L'Education physique el le sport, no Congresso Colonial de Paris.

${ }^{10} \mathrm{O}$ exemplo que melhor ilustra esta situação é a do futebolista Eusébio, um dos mais relevantes jogadores da história do futebol mundial.
} 
sejam os corpos não identificados na convencional dualidade de gênero, os corpos das comunidades indígenas, os corpos em fuga dos refugiados, os corpos pobres sem abrigo, encarcerados, entre outros.

\section{A PROPOSTA INTERVENTIVA DAS EPISTEMOLOGIAS DO SUL}

A bizarria desses dias de 1904, em St. Louis, continua presente nas sistemáticas manifestações de depreciação das performances dos corpos dos outros. "Os outros" são aqueles que se encontram para lá da linha abissal que divide o mundo em duas partes. Linha resultante da dual cartografia moderna, simultaneamente jurídica e epistemológica, que divide a realidade em dois universos distintos: o "lado de cá" e o "lado de lá". Pretensamente, "de um lado" está a ordem, o controle, a estabilidade, a racionalidade, a liberdade e a democracia; "do outro lado" nada existe, há apenas um espaço de abandono, caótico, violento e irracional. "A divisão é tal que 'o outro lado da linha' desaparece enquanto realidade, torna-se inexistente, e é mesmo produzido como inexistente. Inexistência significa não existir sob qualquer forma de ser relevante ou compreensível" (SANTOS, 2007, p. 3-4).

Originalmente, a localização da linha radical, fronteira de mundos distintos, coincidiu historicamente com um território social específico: a zona colonial. Dum lado, as sociedades metropolitanas, do outro os territórios coloniais. Podemos também, como sugere Edgar Morin (2011), numa cartografia relativa, localizar essa linha radical algures entre o norte e o sul, sendo que essa fronteira pode ser sucessivamente empurrada ou puxada para o norte e o sul consoante a localização de cada um. No caso Europeu, é evidente a redefinição de fronteiras, enquanto estratégia de separação do mundo que se diz civilizado e desenvolvido, do mundo julgado incivilizado e subdesenvolvido (NOLASCO; LECHNER; RIBEIRO, 2014). Os corpos que se localizam nesse sul global, que estão para lá da linha abissal, são os corpos possuidores de sinais diacríticos, utilizados como argumento de exclusão e causadores de sofrimento humano. A sua expressividade e motricidade não é apenas desconsiderada, é simplesmente ignorada, verificando-se nestes casos um desperdício da experiência. Essa é uma experiência alternativa, de vida, de motricidade, de ação lúdica, de visão do mundo, que pode constituir um elemento de transformação, uma resposta ao esgotamento paradigmático da modernidade (SANTOS, 2000), e em concreto para o universo desportivo, a possibilidade de outro desporto.

A proposta teórica de resposta à crise paradigmática do tempo presente, e de superação dessa fratura abissal, é a das Epistemologias do Sul. Boaventura de Sousa Santos diz que perante o esgotamento da modernidade, e de propostas subparadigmáticas que advogam um reajustamento estrutural dentro dos limites do capitalismo e da sua dinâmica de globalização, há propostas alternativas de viragem paradigmática com o auspicioso início de uma nova era de solidariedade igualitária ou mesmo cósmica (SANTOS, 1995).

As Epistemologias do Sul são essa alternativa, e enquanto proposta epistemológica constituem pois, a "[...] capacitante afirmação de uma insuspeitada e inesgotável diversidade dos saberes e das experiências humanas" (SANTOS, 2008, p. 21). As Epistemologias do Sul são o conjunto de intervenções epistemológicas que em primeira instância denunciam a supressão de saberes que nos últimos séculos foi conduzida pelo conhecimento hegemônico, em segundo lugar, valorizam e resgatam saberes sonegados e silenciados pelo colonialismo, capitalismo e patriarcado, e em terceiro, propõe um amplo reconhecimento da diversidade de experiências e 
conhecimento do mundo, investigando as condições de um diálogo horizontal entre conhecimentos (SANTOS; MENESES, 2009).

Dois conceitos centrais das Epistemologias do Sul são a sociologia das ausências e a sociologia das emergências. O processo de amplificação do mundo inicia-se com a sociologia das ausências, ou seja, “[...] uma investigação que visa demonstrar que o que não existe é, na verdade, ativamente produzido como tal, isto é, como uma alternativa não credível ao que existe" (SANTOS, 2002, p. 246). Ou seja, através deste exercício procuram transformar-se entidades, relações, conhecimentos, objetos impossíveis em possíveis, e com base neles transformar as ausências em presença, converter invisibilidades em visibilidades. Por sua vez, a sociologia das emergências expande o domínio das experiências sociais possíveis, substituindo o vazio do futuro segundo o tempo linear, por um futuro de possibilidades plurais e concretas, simultaneamente utópicas e realistas, que se vão construindo no presente. Operando em conjunto, a sociologia das ausências ao ampliar a realidade credível, permite que a sociologia das emergências tenha um mais vasto campo de sinais ou pistas credíveis e de futuros possíveis e concretos.

A operacionalização da sociologia das ausências ocorre através da substituição de monoculturas por ecologias. A monocultura do saber da ciência moderna e do rigor científico é substituída pela ecologia dos saberes, ou seja, pela identificação de outros saberes, de outras práticas e procedimentos. A monocultura do tempo linear, com a assunção de que o tempo progride através do desenvolvimento e modernização, é substituída pela ecologia das temporalidades que assume o relativismo do tempo e a possibilidade da coexistência de diferentes temporalidades. A monocultura da naturalização das diferenças, produzindo hierarquias de atributos naturalizados que negam a intencionalidade de hierarquias sociais, é substituída pela ecologia dos reconhecimentos, ou seja, pela possibilidade de diferenças iguais, de reconhecimentos recíprocos, desconstruindo hierarquias e diferenças. A monocultura da escala dominante, nomeadamente a escala universal e global que aprisiona o particular e o local em escalas incapacitantes de serem alternativas, é substituída pela ecologia das trans-escalas, que desglobaliza e desuniversaliza através do recurso a mapas cognitivos que operam simultaneamente em diferentes escalas. A monocultura dos critérios de produtividade capitalista, que visa a maximização da produção e rendimento, seja da natureza ou do trabalho humano, é substituída pela ecologia da produtividade, que colocando em causa o paradigma de acumulação capitalista propõe formas alternativas de produção desacreditadas pelo capitalismo (SANTOS, 2002).

As formas de não existência produzidas pelas monoculturas da razão metonímica são o ignorante, o residual, o inferior, o local e o improdutivo. Estas são as partes desqualificadas da totalidade hegemônica, as partes irrelevantes e desprezadas. A produção destas ausências traduz-se num mundo mais pobre, com menos recursos e possibilidades, empobrecendo o presente e limitando o futuro. A ecologia dos saberes, e as restantes ecologias alternativas às monoculturas, resgatam estas existências, assumem-nas e apresentam-nas como alternativas de um futuro possível. Importa assinalar que a operacionalização da sociologia das ausências e emergências não se traduz na recusa da ciência e dos seus conhecimentos, mas na recusa da sua hegemonia e exclusividade, e na afirmação de conhecimentos e práticas alternativos, em interação e complementaridade.

As Epistemologias do Sul ao proporem-se resgatar a humanidade subalternizada, os seus conhecimentos desvalorizados e ignorados, constituem-se como uma proposta epistemológica subalterna, insurgente, resistente, alternativa contra um projeto de dominação capitalista, colonialista e patriarcal, que continua a ser um paradigma 
hegemônico (SANTOS; ARAÚJO; BAUMGARTEN, 2016), e por isso, esta proposta não é apenas teórica, mas também é um "[...] novo paradigma de compreensão e de articulação (ou coordenação) da ação no mundo" (CASTIANO, 2018, p. 73).

\section{COMPLEMENTARIDAde DAS EPISTEMOlOGias DO SUl COM A MOTRICIDAdE HUMANA}

O desporto, nas suas diversas modalidades, nos variados escalões de competição, e nas inúmeras práticas, que vão do lúdico ao profissional, são parte integrante da motricidade humana. Como diz Manuel Sérgio, “[...] onde o ser humano se movimenta, aí existe o desporto" (1994, p. 128). Não apenas o desporto, mas todas as atividades como a dança, a ergonomia, a reabilitação, para além dos movimentos laborais, educacionais, e ainda os banais movimentos do quotidiano, que aconteçam sobre a base de uma atividade humana prática. Então, a motricidade humana,

[...] ou seja, o corpo em acto, é um espaço de signos de onde emergem a carne, o sangue, o desejo, o prazer, a paixão, a rebeldia, emoções e sentimentos do mais variado tipo. E tudo isto, visando a transcendência, ou a superação. Mas porque é transcendência, a conduta motora (a acção) acrescenta alguma coisa ao Mundo através do inesperado, do novo, do insólito (SÉRGIO, 2010, p. 117).

Assim entendia, "[...] a motricidade humana, sendo um valor a atingir de forma irrenunciável, transforma-se em itinerário obrigatório de todos os valores" (SÉRGIO, 1994, p. 36). Esta conceituação da motricidade humana tem como pressuposto a existência de um ser práxico, que na totalidade corpo-alma-natureza-sociedade, pelo movimento procura transcender e transcender-se. Manuel Sérgio assume assim uma totalidade complexa, do ser humano. Há, nesta proposta da totalidade humana, o mesmo sentido de totalidade que Edgar Morin propõe no seu Método para abordar a complexidade humana: a natureza da natureza, a vida da vida, o conhecimento do conhecimento, as ideias, a humanidade da humanidade, e a ética ${ }^{11}$. Estes são os constituintes do todo complexo em que o ser humano se constitui, num contínuo que vai do infinitamente pequeno ao infinitamente grande, passando pela dimensão biológica, antropológica e social, ou seja, um tecido de constituintes heterogêneos inseparavelmente associados, que condensam em si o uno e o múltiplo (MORIN, 1995).

O desporto, com a pluralidade de movimento que tem implícita, com os sentidos que lhe são inerentes, é um elemento relevante desta assunção complexa do ser humano.

\footnotetext{
O desporto, ao mesmo tempo que revela, promove a dignidade humana. Revela, porque mostra o ser humano no movimento lúdico-agonístico da transcendência; promove, porque é a um tempo procura e manifestação do humano, nas suas raízes e no seu projecto fundamental; promove ainda porque é fidelidade ao homem e à sua lúcida esperança de sê-lo inteiramente (SÉRGIO, 1994, p. 150).
}

A proposta da motricidade humana em assumir o desporto na sua complexidade psicossomática, antropossocial e ético-filosófica, com o conjunto específico de movimentos e gestos que intencionalmente tendem para a transcendência, assume uma ruptura epistemológica para com o paradigma cartesiano. O corpo desportivo, à

\footnotetext{
${ }^{11}$ Estes são os títulos dos seis volumes de O Método da autoria de Edgar Morin, publicados originalmente entre 1977 e 2004.
} 
semelhança de todos os outros corpos foi concebido como res extensa, ou seja, uma substância anexa e dependente, que está no espaço com a sua massa, forma e movimentos, funcionando de forma puramente mecanicista. Esta foi a perspectiva paradigmática que legitimou o evento dos Dias Antropológicos de St. Louis: os corpos atléticos, educados fisicamente por uma res cogitans forte, por oposição aos corpos nativos sujeitos a uma res cogitans débil. A proposta da Motricidade Humana, tal como formulada por Manuel Sérgio, resolve esta fratura entre o físico e o espírito, não apenas por efetivar um corte epistemológico com o racionalismo cartesiano, mas por propor também a alternativa de se assumir o ser humano como entidade complexa, em que para além das dimensões físicas e espirituais, comporta ainda o entorno social de pertença. Por consequência, o gesto desportivo, para além de um gesto físico, é também um gesto pessoal, cultural e político. Esta assunção proporcionada pela Motricidade Humana é extremamente relevante, na medida em que permite fundamentar a argumentação de que o desporto, não é um fenômeno meramente físico e mecânico, nem tão pouco unidimensional na forma como acontece, antes pelo contrário, é um fenômeno sócioantropológico complexo e contraditório, condensando em si uma multiplicidade de dimensões.

Entre a Motricidade Humana e as Epistemologias do Sul há, desde logo, uma aspiração comum: superarem uma limitada perspectiva racionalista e paradigmática de interpretação do movimento e do mundo. Olhando para o desporto, essa aspiração traduz-se na superação de um modelo "ortopédico"12 de formatação de toda a atividade desportiva. O processo de desportivização (ELIAS; DUNNING, 1992, p. 59) ocorrido ao longo do século XIX, entre outras dimensões, foi também marcado por um conjunto de aspectos, que inter-relacionados, determinaram o modelo hegemônico de desporto, nomeadamente: a secularização na orientação das práticas; a igualdade na possibilidade de participação; a burocratização na administração e organização da modalidade; a especialização no sentido da diferenciação consoante as aptidões e as estratégias técnicas e táticas; a racionalização não só do desempenho físico, mas também das regras para maior rentabilidade e espetacularidade; a quantificação que permite comparar marcas, resultados e desempenhos; a obsessão pelo recorde e o desafio em superá-lo (GUTTMANN, 1994). Todos os elementos, referidos como características do desporto, estão inscritos no modelo das ciências modernas, constituindo-se como critérios de organização social. Esse modelo "ortopédico" de sport ${ }^{13}$ aplicou-se aos jogos prémodernos, obrigando a uma reconversão progressiva a marcos de racionalidade, motricidade e organização caraterísticos do modelo de sport. Os jogos que subsistem, ou aqueles que emergirão, são marcados por essa formatação gradualmente mais organizada, burocratizada, institucionalizada, racionalizada, regulada, especializada e normalizada, como se pode constatar nas várias modalidades desportivas. Os restantes serão remetidos para uma dimensão meramente folclórica. A superação desta formatação ortopédica é feita, por um lado, pela Motricidade Humana através da ruptura

12 Boaventura de Sousa Santos (2008) argumenta que o pensamento ortopédico consiste no constrangimento e empobrecimento causado pela redução da realidade a marcos analíticos e conceituais previamente determinados pelo pensamento científico. Pelo que, a realidade tem que se adaptar a esse modelo de conceber o mundo, sendo que as dimensões que não se adaptarem serão ignoradas.

${ }^{13}$ Esse modelo ortopédico de desporto que se impõe é o britânico. A Inglaterra foi o país que mais cedo reuniu as condições de desenvolvimento e modernidade para a gênese do desporto moderno, pelo que partir de então, o modelo british de desporto rapidamente se expandiu pelo mundo. Progressivamente, como se de um desenvolvimento civilizante se tratasse (BALE, 1989), todos os espaços que estavam em contato com o império britânico foram adotando esse modelo desportivo. A Inglaterra significava modernidade, o conceito de sportmen traduzia essa modernidade, daí a adesão incondicional ao modelo que espelhava essas caraterísticas. 
com o cartesianismo, e pela aceitação da complexidade do ser humano que se move, e por outro, é feita pelas Epistemologias do Sul através da crítica ao paradigma científico dominante e pela busca de alternativas de conhecimento no Sul global.

O mais significativo contributo que as Epistemologias do Sul possam ter para com a Motricidade Humana, consiste na proposta de intervir epistemologicamente através da operacionalização da sociologia das ausências, da sociologia das emergências, e da ecologia dos saberes. Através da sociologia das ausências, a Motricidade Humana conseguirá resgatar corpos, movimentos e gestos e as consequentes práticas lúdico-desportivas que foram desprezadas pelo colonialismo, pelo patriarcado e pelo capitalismo. Esse resgate deverá incidir sobre os desprezados movimentos dos corpos indígenas, e de todos os que são escamoteados pelas modernas formas de colonialidade global; os desconsiderados movimentos dos corpos das mulheres, e de todas as sexualidades não convencionais, desrespeitados por modernas formas de patriarcado global; os desvalorizados movimentos dos corpos dos pobres e miseráveis, daqueles que não têm valor econômico, vilipendiados pela voracidade do capitalismo selvagem. Estes corpos que estão para lá da linha abissal existem, têm dignidade, têm conhecimento, movimentam-se, jogam, praticam desporto, e nos seus gestos, têm igualmente uma intencionalidade que tende para a transcendência. Transcendência que não é, nem tem que ser coincidente com a que se almeja do lado de cá da linha abissal. Em vez de uma transcendência que tende para a superação individual, pode estar uma transcendência que tende para um sentido de comunidade, para um sentimento de dignidade, para a afirmação de existência própria. Através da sociologia das emergências, estes corpos e movimentos resgatados, poderão ampliar o leque de expressividades, de performances, de praxis lúdica e desportiva, de um universo de movimentos que esteve limitado aos hegemônicos corpos e movimentos do norte global. A ecologia dos saberes que permite futuros possíveis e concretos, será tanto mais eficaz quanto também se afirme uma ecologia dos movimentos humanos por oposição a uma monocultura da cultura física, e que ofereça um amplo campo de miscigenação intercultural em prole de um futuro credível.

Uma eventual crítica que se pode fazer à Motricidade Humana está relacionada com o fato de se fundamentar no modelo hegemônico de conhecimento científico, fato que está desde logo patente na designação que Manuel Sérgio lhe atribui: ciência da motricidade humana (1994). Desde a perspectiva das Epistemologias do Sul, a categorização dos conhecimentos em ciência e numa subsequente estrutura organizativa que visa a compreensão e ordenação do saber, ao mesmo tempo que disciplina o conhecimento, procede a uma divisão de saberes com desigual nível estatutário, “[...] criando outras formas de opressão, que perpetuam a divisão abissal da realidade social" (MENESES, 2008, p. 6). A Motricidade Humana aceita essa dimensão científicodisciplinar, intitulando-se precisamente "ciência", fundamentando-se num quadro teórico de reflexão preenchido por referências filosóficas, e assumindo uma metodologia de investigação, o método integrativo (PEREIRA, 2011), que legitime academicamente o conhecimento produzido. Não se quer dizer com isto que a Ciência da Motricidade Humana não tenha valor apenas pelo fato de ser ciência. Deve referir-se que as Epistemologias do Sul não recusam a ciência moderna e que reconhecem os méritos dos seus conhecimentos, recusando sim a sua hegemonia e exclusividade, afirmando a possibilidade de outros conhecimentos válidos e úteis. Nem tão pouco se afirma que a Ciência da Motricidade Humana não reconheça a praxis de outras latitudes. Apenas se convida a Motricidade Humana a libertar-se do espaço acadêmico, e ultrapassar a linha abissal em busca de outros gestos, movimentos e transcendências. Neste âmbito, as Epistemologias do Sul, têm no projeto da Universidade Popular dos 
Movimentos Sociais um espaço privilegiado para articular os conhecimentos diversos, fortalecendo novas formas de resistência e contribuindo para a reinvenção da emancipação social, entendida aqui como a base em que projetos plurais transformam relações de poder em relações de autoridade partilhada ${ }^{14}$. Também se pode invocar que as Epistemologias do Sul têm origem no espaço do formalismo acadêmico, contudo, desde o primeiro momento que esta proposta de conhecimento se predispôs para aprendizagens mútuas, "[...] assente em três orientações: aprender que existe o Sul; aprender a ir para o Sul; aprender a partir do Sul e com o Sul" (SANTOS, 1995, p. 508).

\section{CONSIDERAÇÕES FINAIS}

A abordagem crítica que se fez ao desporto, em diversos momentos deste texto, não incide particularmente sobre a essência do desporto, que é o jogo, mas sobre as várias camadas sociais que lhe vão sendo aplicadas, convertendo-o em algo mais do que um simples jogo. Por exemplo, a essência de um jogo de futebol não é significativamente distinta se for disputado no recreio de uma escola ou no mais midiático dos estádios. Os gestos, as regras e os objetivos são sensivelmente os mesmos, e ganha quem mais gols marcar. No entanto o jogo da escola é isso mesmo, um jogo, enquanto o jogo no estádio vai sofrendo metamorfoses em virtude da racionalização técnico-tática, da profissionalização dos jogadores, do mediatismo da comunicação social, do valor econômico que está implícito, do eventual sentido político e de muitas outras variáveis. Este jogo metamorfoseado foi instrumento de colonização, mapeamento patriarcal e matéria de capitalismo. E por isso, apesar de este jogo ser porventura a mais global das expressões de cultura popular, a sua expressão hegemônica ocorre essencialmente nos clubes europeus, na variante masculina, e sob a égide da lógica capitalista de maximização do rendimento. O jogo de futebol propriamente dito, os gestos e movimentos dos jogadores, tendem para a transcendência conforme enunciado da Motricidade Humana, contudo a indústria do futebol de alta competição converteu-se numa forma de fascismo social pelo seu caráter impositivo, pela forma como esgota as possibilidades emancipatórias de outras variantes de jogos. (NOLASCO, 2015).

Outro desporto é possível? Sim, outro desporto é possível! Um exemplo dessa possibilidade é dado pelo fútbol callejero, nascido e criado no Sul (BELMONTE; GONÇALVES JUNIOR, 2018). Um futebol de regras próprias, estabelecidas pelos próprios jogadores e jogadoras, com base nos princípios de respeito, cooperação e solidariedade, decidem a forma de tornar o jogo mais justo e equilibrado. Um futebol que quase foi cooptado pela poderosa Fédération Internationale de Football Association, mas que conseguiu emancipar-se da sua ideologia comercial. Um futebol nascido em Buenos Aires, e jogado em muitos outros lugares do Sul, num processo de constante reinvenção e reconfiguração no espaço e tempo. Um futebol de uma sociologia de ausências e de uma motricidade emergente, jogado por quem vive, luta e resiste, "favorecendo a práxis humana de ser mais".

Longe vão os dias Antropológicos de St. Louis, contudo a ambivalência do mundo, entre possibilidades e ameaças, ao mesmo tempo em que cria condições para a afirmação de corpos escamoteados pelas múltiplas faces do colonialismo, patriarcado e capitalismo, cria outros corpos invisíveis, sem espaço para o exercício digno e emancipatório de gestos e movimentos. A fratura abissal entre o norte global e o sul

\footnotetext{
${ }^{14}$ A este propósito ver 〈http://www.universidadepopular.org/site/pages/pt/em-destaque.php?lang=PT>. Acesso em: 16 out. 2019.
} 
global, não é uma mera figura de estilo, mas uma realidade concreta e brutal, quotidianamente testemunhada por quem a pretende atravessar. Os corpos dos africanos subsaarianos que numa motricidade de sofrimento procuram atravessar o Mediterrâneo, os corpos dos centro-americanos que numa práxis de dignidade buscam o outro lado da fronteira dos Estados Unidos, ou os corpos dos sírios que numa mobilidade de sobrevivência procuram sair do seu país, são os corpos de uma humanidade que inevitavelmente se confronta com as incongruências do tempo presente. São os corpos que não se emanciparam num intenso processo de globalização, e que permanecem localizados nas suas aldeias indígenas, nas periferias das grandes cidades, nos bairros sociais, nas favelas, que trabalham nas minas, na agricultura, nas fábricas, que têm o sustento ameaçado, que têm uma vida precária. Os corpos destes homens e mulheres não podem frequentar ginásios, pavilhões, relvados, piscinas, porque são equipamentos demasiado caros para o seu nível de vida, ou simplesmente não existem nos lugares onde vivem. A motricidade desportiva convencional, institucionalizada torna-se assim inacessível. Contudo, como qualquer outro corpo de "[...] um ser práxico que, na totalidade corpo-alma-natureza-sociedade e pela motricidade, procura transcender e transcender-se" (SÉRGIO, 1994, p. 26), também esses corpos nascidos e sofridos no Sul global, são corpos desportivos. Para alguns a ultrapassagem da linha abissal ocorre através de processos migratórios desportivos, migrando para os clubes do sul global na miragem da glória ou simplesmente da sobrevivência, para os outros que ficam resta a rua, os espaços abertos, e a possibilidade de recriarem motricidades que os emancipem, dignifiquem e transcendam.

As Epistemologias do Sul, com os seus conceitos operacionais de sociologia das ausências, sociologia das emergências e ecologia dos saberes, bem como a Motricidade Humana, com as respectivas referências e metodologias integrativas, mais do que estudar, conhecer e entender, têm a responsabilidade de emancipar, dignificar e sublimar, através de um trabalho de descolonização, despatriarcalização e descapitalização (BELMONTE; GONÇALVES JUNIOR, 2018) as motricidades emergentes. Só assim é possível outro desporto, outra motricidade, que através de uma ecologia de gestos e movimentos permita superar a fratura abissal do mundo. Só assim as Epistemologias do Sul e a Motricidade Humana serão uma alternativa emergente para a ambivalência do atônito tempo contemporâneo, do tempo em que, como disse Immanuel Wallerstein (1998) ${ }^{15}$, podemos mudar o mundo.

\section{REFERÊNCIAS}

BALE, J. Sports Geography. Londres: E. \& F.N. Spon, 1989.

BELMONTE, M. M.; GONÇALVES JUNIOR, L. Fútbol callejero: nascido e criado no Sul. Revista Crítica de Ciências Sociais, n. 116, p. 155-177, 2018.

BESNIER, N.; BROWNELL, S. Sport, modernity, and the body. Annual Review of Anthropology, v. 41, p. 443-459, 2012.

BROWNELL, S. (Org.). The 1904 Anthropology Days and Olimpic Games. Sport, Race, and American Imperialism. Nebraska: University of Nebraska, 2008.

CASTIANO, J. P. Apresentação. Motricidades, v.2, n.2, p. 73-75, 2018.

\footnotetext{
${ }^{15}$ Esta referência é uma modesta homenagem a Immanuel Wallerstein, falecido em 31 de agosto de 2019, e que para além de um dos mais proeminentes cientistas sociais, foi um sociólogo comprometido com o seu tempo e combatente da implosão do capitalismo.
} 
DOMINGOS, N. Futebol e colonialismo. Lisboa: Imprensa de Ciências Sociais, 2012.

DOMINGOS, N. Futebol e colonialismo, dominação e apropriação: sobre o caso moçambicano. Análise Social, n. 179, p. 397-416, 2006.

EICHBERG, H. Olympic Anthropology Days and the Progresso f Exclusion. Toward na Anthropology of Democracy. In: BROWNELL, S. (Org.). The 1904 Anthropology Days and Olimpic Games. Sport, Race, and American Imperialism. Nebraska: University of Nebraska, 2008. p. 343-382.

ELIAS, N.; DUNNING, E. A Busca da excitação. Lisboa: Difel, 1992.

GIDDENS, A. As consequências da mmodernidade. Oeiras: Celta Editora, 1992.

GUTTMANN, A. Games \& empires. Modern sport and cultural imperialism. Nova Iorque: Columbia University Press, 1994.

HOBSBAWM, E. Era dos extremos. Queluz: Editorial Presença, 1994.

LUCAS, C. J. P. (1905). The Olympic Games, 1904. St. Louis: Woodwabd \& Tlbknan Printing, 1905. Disponível em: <https://digital.la84.org/digital/collection/p17103coll8/id/8216/>. Acesso em: 2 out. 2019.

MALLON, B. The 1904 Olympic Games: Results for All Competitors in All Events, with commentary. Jefferson: MCFarland \&Company, 1994.

MAUSS, M. Sociologie et anthropologie. París, Ed. PUF, 1966.

MENESES, M. P. O 'indígena' africano e o colono 'europeu': a construção da diferença por processos legais. E-Cadernos CES, n. 7, p. 68-93, 2010.

MENESES, M. P. Introdução às Epistemologias do Sul. Revista Crítica de Ciências Sociais, n. 80, p. 510,2008

MOLINARI, C. Os Jogos Antropológicos de 1904: o esporte a favor do racismo. Historiadores dos Esportes, 2018. Disponível em: <https://historiadoresdosesportes.com/2018/10/01/os-jogosantropologicos-de-1904-o-esporte-a-favor-do-racismo/>. Acesso em: 2 out. 2019.

MORIN, E. Para um pensamento do Sul. In: SALMITO, A.; FADEL, C.; IRVING, M. (Orgs.). Para um Pensamento do Sul. Diálogos com Edgar Morin. Rio de Janeiro: Serviço Social de Comércio, 2011. p. 921.

MORIN, E. Introdução ao Pensamento Complexo. Lisboa: Instituto Piaget, 1995.

NOLASCO, C. Bola prá frente! Em busca de outro futebol. In: SANTOS, B. S.; CUNHA, T. (Orgs.). Atas do Colóquio Internacional Epistemologias do Sul: aprendizagens globais Sul-Sul, Sul-Norte e Norte-Sul (Vol. III). Coimbra: Centro de Estudos Sociais, 2015. p. 491-503.

NOLASCO, C.; LECHNER, E.; RIBEIRO, J. Reflexos invertidos: as migrações clandestinas no filme de ficção e documentário. Revista Crítica de Ciências Sociais, n. 105, p. 87-92, 2014.

PEREIRA, A. P. A ciência da motricidade humana e as suas possibilidades metodológicas. Filosofia e Educação, v. 2, n. 2, p. 376-392, 2011.

SANTOS, B. S. A filosofia à venda, a douta ignorância e a aposta de Pascal. Revista Crítica de Ciências Sociais, n. 80, p. 11-43, 2008.

SANTOS, B. S. Para além do Pensamento Abissal: das linhas globais a uma ecologia dos saberes. Revista Crítica de Ciências Sociais, n. 78, p. 3-46, 2007. 
SANTOS, B. S. Para uma sociologia das ausências e uma sociologia das emergências. Revista Crítica de Ciências Sociais, n. 63, p. 237-280, 2002.

SANTOS, B. S. A crítica da razão indolente: contra o desperdício da experiência. Porto: Afrontamento, 2000.

SANTOS, B. S. Toward a New Common Sense. Law, Science and Politics in the Paradigmatic Transition. Nova Iorque: Routledge, 1995.

SANTOS, B. S.; ARAÚJO, S.; BAUMGARTEN, M. As epistemologias do sul num mundo fora do mapa. Sociologias, v. 18, n. 43, p. 14-23, 2016.

SANTOS, B. S.; MENESES, M. P. (Orgs.). Epistemologias do Sul. Coimbra: Almedina, 2009.

SÉRGIO, M. O desporto e a motricidade humana. Caderno de Educação Física, v. 9, n. 16, p. 111-122, 2010 .

SÉRGIO, M. Motricidade humana. Lisboa: Instituto Piaget, 1994.

UNITED NATIONS. Global Multidimensional Poverty Index (MPI) 2019 Illuminating Inequalities. Nova Iorque: United Nations Development Programme, 2019. Disponível em: <http://hdr.undp.org/sites/default/files/mpi_2019_publication.pdf>. Acesso em: 24 out. 2019.

VAN DER MERWE, F. Africa's first encounter with the Olympic games in... 1904. Journal of Olympic History, v. 7, n. 5, p. 29-34, 1999.

WALLERSTEIN, I. Utopistics: Or Historical Choices of the Twenty-First Century. Nova Iorque: The New Press, 1998.

Recebido em: 28 out. 2019.

Aprovado em: 03 dez. 2019. 